\title{
A Tale of a Two Waves Epidemic: Characteristics and Mortality Risk Factors for COVID-19 ICU Patients in the French West Indies
}

jean-david Pommier

Pasteur Institut of Guadeloupe: Institut Pasteur de Guadeloupe

frederic Martino

Universite des Antilles et de la Guyane

Kevin Bleakley

Inria

Laure Flurin

Mayo Clinic College of Medicine and Science

Fabien Van Roy

UAG: Universite des Antilles et de la Guyane

michel Carles

Universite des Antilles et de la Guyane

marc Valette

Universite des Antilles et de la Guyane

laurent camous ( $\sim$ laurent.camous@chu-guadeloupe.fr)

Universite des Antilles et de la Guyane https://orcid.org/0000-0002-0265-429X

\section{Research}

Keywords: COVID19, epidemic, Acute Respiratory distress syndrome, population, Pulmonary fibrosis, Epidemiology, Ventilator Associated Pneumonia

Posted Date: February 9th, 2021

DOl: https://doi.org/10.21203/rs.3.rs-200243/v1

License: (c) (i) This work is licensed under a Creative Commons Attribution 4.0 International License. Read Full License 


\section{Abstract}

\section{Introduction}

Guadeloupe, a French West Indies island, has been fiercely affected by two large waves of COVID.

Therapeutic approach was different between the two waves in the intensive care unit (ICU).

We aimed to compare the two different periods in terms of characteristics and outcomes and to evaluate risk factors associated with 60-day mortality in our overall cohort.

\section{Methods}

All consecutive patients with laboratory confirmed COVID-19 pneumonia and requiring oxygen support admitted in our ICU unit of University Hospital of Guadeloupe were prospectively included. Patients were treated during the first wave with a combination of Hydroxychloroquine and Azithromycin and during the second wave with dexamethasone and reinforced anticoagulation.

\section{Results}

In our cohort, 187 patients were included, 31 during the first one and 156 during the second. Patients were mostly male (69\%) with a median age of 64years old. Patients tend to be younger during the second wave and body mass index was higher (respectively $31 \mathrm{vs} 27 \mathrm{~kg} / \mathrm{m} 2, \mathrm{p}=0.01$ ). Overall mortality at Day 60 was high (45\%) and not different between the two waves. Among patients under mechanical ventilation risk factors associated with death in a multivariate analysis were a high number of comorbidities, a high level of SOFA score and the delay of invasive mechanical ventilation (IMV) onset after admission in ICU $(\mathrm{OR}=1.6(95 \% \mathrm{Cl} 1.2-2.4)$.

\section{Conclusion}

Although therapeutics approach evolve, COVID-19 severe pneumonia is still associated with a high mortality rate in ICU.

\section{Introduction}

Coronavirus disease 2019 (COVID-19) pandemic has been, since it was first described ${ }^{1}$, a field of investigation for physicians worldwide. Since March 2020, Guadeloupe, a French Caribbean island has been affected by two large waves of COVID-19 cases. During the first wave, (March to May 2020), the disease was poorly understood and had no effective treatment. Since then, large studies have been published ${ }^{2}$ and have identified prognostic factors related to the host and the level of organ dysfunction.

Since the beginning of the outbreak, specific SARSCOV2 therapy has been intensively searched ${ }^{2-3}$. 
During the first wave, we used hydroxychloroquine with azythromycin, as no therapy was clearly identified at that time. Standard of care has greatly evolved since and now includes steroids ${ }^{3-5}$ due to preliminary data suggesting reduced 30-day mortality ${ }^{2,3}$. COVID-19 has also been shown to be associated with coagulopathy and a high risk of thrombosis, and several sets of guidelines suggest to keep upkeeping a sufficient level of anticoagulation among SARSCOV2 infected patients ${ }^{6-10}$. New drugs are still under evaluation ${ }^{6}$ though there is no great consensus on their use at this time. Currently, whether any therapeutic approaches have an impact on morbi-mortality remains unclear ${ }^{11}$. We report here our cohort of patients admitted to an intensive care unit (ICU) with COVID-19 laboratory confirmed severe pneumonia during the two main waves in 2020. We compared the two groups in terms of clinical characteristics and outcomes. We also evaluated risk factors associated with 60-day mortality in these critically ill patients.

\section{Methods}

\section{Population selection and study design}

COROCARA is a single center prospective cohort study conducted in the ICU of the University Hospital in Guadeloupe. All patients over 18 years of age with COVID-19 pneumonia and hospitalized in the ICU during the two COVID-19 outbreaks from March-May (first wave) and August-October (second wave) were included in the study. COROCARA received approval from the ethics committee of the University Hospital in Guadeloupe. Laboratory confirmation was defined as a positive result by real-time reverse transcriptase-polymerase chain reaction (RT-PCR) assay from either nasopharyngeal swabs or lower respiratory tract aspirates. All included patients had a laboratory confirmed diagnosis.

\section{Data collection}

All clinical and biological data were collected within the first twenty-four hours after ICU admission. For each patient we collected the following clinical data: age, sex, body mass index (BMI), comorbidities, immunodeficiency, treatment received, the Simplified Acute Physiology Score (SAPS) II score ${ }^{12}$, the Sequential Organ Failure Assessment (SOFA) ${ }^{13}$ score, date of first symptoms, dates of hospital and ICU admission, support devices (oxygen mask, high flow nasal cannula, or non-invasive ventilation (NIV)) at admission, or IMV. Routine laboratory data included blood cell count, electrolytes dosages, liver enzymes, blood cultures, blood gas, creatine phosphokinase (CPK), D-dimeres and troponin. When possible, each patient underwent a chest computed tomography before admission.

\section{Syndrome and outcome}

ARDS was graded based on the Berlin Definition ${ }^{14}$ for patients undergoing mechanical ventilation (invasive or non-invasive). To be comparable to other previously published studies, ARDS was only 
graded in patients receiving mechanical ventilation on ICU day 1 . In this study, ICU-complications and organ dysfunction included acute kidney failure requiring renal replacement therapy, pulmonary embolism (proven by pulmonary CT angiography), ventilator-associated pneumonia, and cardiac arrest. Clinical suspicion of ventilator-associated pneumonia was confirmed before antibiotics either by blind protected specimen brush growing $\geq 103 \mathrm{cfu} / \mathrm{mL}$, or endotracheal aspirates growing $\geq 106 \mathrm{cfu} / \mathrm{mL}$. Patient outcome was recorded at the ICU or at hospital discharge. A favourable outcome was defined as a patient who was alive at day 60 after admission.

\section{Treatment}

Standard of care was different during the first and second wave, due to an increased availability of data and results in the literature over time and an improving understanding of the disease. Hydroxychloroquine was initially used during the first wave in combination with azithromycin in our center, even though its use was debated at the time. Dexamethasone (steroids) was systematically used for severe patients requiring oxygen during the second wave, and at the discretion of the physician during the first. In the second wave, anticoagulation was reinforced, systematic screening for pulmonary embolism was performed, and NIV and high flow oxygen were used. The use of mechanical ventilation was at the discretion of the physician.

\section{Statistical analysis}

All analyses were performed using R 4.0.4 ${ }^{15}$. Data are reported as median (interquartile range) or number (percentage). The baseline data are reported from the twenty-four hours period after ICU admission. No sample size calculations were performed. Univariate characteristics of the two cohorts (first and second wave) were compared using chi-square or Fisher's exact tests for categorical variables and using Student's t-test or Wilcoxon's rank-sum test for continuous variables. Kaplan-Meier overall survival curves up to day 60 were computed separately for first wave and second wave patients, and in patients with delayed mechanical ventilation (>4 days after ICU admission) vs those mechanically ventilated starting in the first four days after treatment administration. No imputation was performed for missing values. We furthermore ran a multivariate analysis to asses risk factors for death in patients requiring IMV. The final set of variables to be included in the multivariate logistic model were chosen on the basis of pathophysiological interest and the requirement $p<0.2$. We performed backward selection on the model, stopping when the Akaike information criterion (AIC) reached its minimum.

\section{Results}

\section{Patients Enrolled}

Patient characteristics and their day 1 vital status are described in Table 1, Patients were majority male $(n=129,69 \%)$ with median age 64 years $(54-71)$. Within twenty-four first hours, the median SAPS II was 
34 (24 - 46) and the median SOFA was 4 (3 - 8). Patient characteristics were strikingly similar between the two waves for most of evaluated variables. Median respiratory rate and median Body-Mass Index were higher during the second wave (respectively, $34 \mathrm{vs} 31 / \mathrm{min}, \mathrm{p}=0.03$, and $30.9 \mathrm{vs} 27.2 \mathrm{~kg} / \mathrm{m}^{2}, \mathrm{p}=0.01$ ). Few patients had a bacterial coinfection at admission $(n=10,6 \%)$.

\section{Ventilatory support, adjunctive therapies, and ARDS severity comparison}

Within the first twenty-four hours, first wave patients more often received invasive mechanical ventilation (IMV) (45\% vs $39 \%)$. In the second wave, patients often received high flow oxygen or NIV ( $51 \%$ vs $0 \%$ ) (Table 2). However, there was no significant difference regarding requiring IMV at some point during ICU hospitalization between the two periods $(71 \%$ vs $63 \%$ of patients $(p=0.47))$. Mechanical ventilationassociated therapies used for ARDS management including prone positioning ( $n=85,71 \%$ in total) and the use of a neuromuscular blockade ( $n=106,89 \%$ in total), were not significantly different between the two waves (Table 2).

\section{$\underline{I C U}$ complications and organ support in patients requiring mechanical ventilation}

Ventilator-associated pneumonia was diagnosed in $50 \%$ of patients who received IMV while $25 \%$ had acute kidney failure requiring renal replacement therapy. No statistical differences were observed between the two waves for these two variables. Median length of IMV was longer among patients during the first wave rather than in patients during the second wave (respectively 20 days vs $7, p<0.001$ )

\section{Patient outcomes and predictors of 60-day mortality}

Results of the univariate and multivariate analysis are reported in Table S1, S2 and Table 3. NonSurvivors within 60 days were older, had more comorbidities at admission than survivors (OR $95 \% \mathrm{Cl}$ : $1.65[1.1 ; 2.7], p=0.04$ ) and had much higher renal and hemodynamic SOFA component scores. Time to mechanical ventilation was also associated with death within 60 days with an $\mathrm{OR}$ of $1.6(95 \% \mathrm{Cl} 1.2-$ 2.4).

Kaplan-Meier survival curves are presented in Figure 1. There were no statistical differences in mortality rates between the two periods. During the second wave, high flow oxygen and NIV were often used as first-step therapy (51\% of patients within the first twenty-four hours), thus delaying IMV for $25 \%$ of the patients (39/156).

The study of the delay between dexamethasone and IMV revealed a subgroup of patients characterized by high case fatality rate $(89 \%, n=16 / 18)$ with a significant difference $(p=0.04)$ when comparing patients under mechanical ventilation 4 days after dexamethasone onset versus patients under mechanical ventilation less than or equal 4 days after dexamethasone onset (see Figure 1B)

\section{Discussion}


We report here a cohort of patients corresponding to the two first waves of the COVID-19 outbreak from the ICU of the University Hospital in Guadeloupe. Despite improvement in terms of ventilatory support and treatment severe COVID-19 pneumonia continued to be grieved with a high mortality rate.

Overall mortality was $44 \%$ and was higher in the elderly and those with multiple organ dysfunction, as previously reported ${ }^{2}$. Unexpectedly, mortality rate were similar in both waves, even after dexamethasone became part of standard of care in the second wave for patients requiring oxygen.

These results should however be interpreted with caution due to several potential biases. First, there could be a "magnifying glass" effect for the second wave patients., In our ICU, admission criteria were tightened and only patients requiring high flow oxygen or immediate IMV were admitted at that time.

SAPS II is known to poorly predict severity of ARDS and that could explain the similarity of patients at baseline between the two waves $(p=0.87)$. Secondly, in our institution, second wave was characterized by $>100 \%$ COVID-19 patient bed occupancy, at contrary of the first wave. During periods of care system overload $^{16}$, mortality tends to be higher compared to less strained ones. This could also be one of the explanations for similar mortality rates.

Strikingly, in our center, need for IMV were similar in both waves ( $64 \%$ of the patients), despite the more systematic use of steroids in the second wave. Rates of IMV was nevertheless lower than previously described in other centers 2,17 .

In univariate analysis, VAP occurrence was associated with higher mortality. Its increased frequency in COVID-19 patients compared to standard ARDS patients has been previously described ${ }^{18,19}$. Consistent with these datas, our incidence of VAP in IMV patients was very high (50\%), with no statistical differences between the two periods however the length of IMV was longer during the second wave.

Our multivariate analysis among patients under IMV with respect to survival revealed several factors of interest. As previously described ${ }^{2}$, older age, comorbidities and severity at admission assessed by SOFA score were highly predictive of death. The burden of these factors is well known ${ }^{2,17}$ and has been extensively discussed elsewhere.

More interestingly, delay between admission to the ICU and IMV onset was predictive of mortality in patients. In the subgroup whose IMV began more than four days after admission to the ICU $(n=18,10 \%$ of patients), mortality was very high $(n=16,89 \%)$.

Several explanations for this finding are possible. First, like many physicians, we used NIV in COVID-19 patients with hypoxemia. Independent of COVID-19, poor prognosis after failure of NIV has already been described in ARDS patients ${ }^{20}$ and with a potentially worsening of lung damage due to self-inflicted lung injury ${ }^{21}$. In this pandemic, NIV has been recommended by other authors for COVID-19 pneumonia management ${ }^{19}$, but we believe that this should be done with caution with early reappraisal to avoid late IMV 
Secondly, besides this physiological explanation, we believe that such grim outcomes could also reflect the pulmonary fibrotic evolution of COVID-19 pneumonia. This pathological finding has already been described in earlier reports ${ }^{22,23}$. We seriously consider this hypothesis here due to the similarity of mechanical ventilation measurements in this subgroup compared to patients with idiopathic pulmonary fibrosis (data not shown). Larger studies are needed to confirm this result due to its potential impact.

We acknowledge several limitations to our study. First, it is monocentric. However, high standardization of COVID-19 care in our unit and results in accordance to larger cohorts advocate for its reliability. Second, the two periods were highly dissimilar in terms of strains on resources. Second wave was characterized by intense clinical activity and overloaded care system. We cannot rule out a negative effect on the survival of second wave patients.

\section{Conclusions}

In this study of 187 critically ill patients with laboratory-confirmed COVID-19 admitted to our ICU, overall, 60 -day mortality was $44 \%$ with no significant difference between the first and second waves. Mortality increased with the number of comorbidities, delayed mechanical ventilation and the SOFA score.

\section{Declarations}

- Our research was approved by our local ethics committee. All patients or families were informed of the data collection.

- We give consent for publication

- All datas and materials are available

- No fee was received for this study and we declare no competing interests

- No fundings

- JDP and LC contributed equally to data collection and writings. LF and FVR helped for data collection. FM, KB, MV and $\mathrm{MC}$ helped for manuscript writings

- We wanted to acknowledge all doctors, residents, nurses, caregiver in charge of patients during all COVID-19 outbreak in the intensive care unit of Guadeloupe. We especifically want to thanks our colleagues Dr Pons, Dr Piednoir, Dr Fleury, Dr Ardisson, Dr Lawson, Dr Paulo, Dr Delamare, Dr Riaud, Dr Amouyal and Dr Elie and all the physicians who came from oversea to help us faced the work overload.

\section{References}

1. Chen N, Zhou M, Dong X, et al. Epidemiological and clinical characteristics of 99 cases of 2019 novel coronavirus pneumonia in Wuhan, China: a descriptive study. Lancet Lond Engl 2020;395(10223):50713. 
2. COVID-ICU Group on behalf of the REVA Network and the COVID-ICU Investigators. Clinical characteristics and day-90 outcomes of 4244 critically ill adults with COVID-19: a prospective cohort study. Intensive Care Med 2021;47(1):60-73.

3. RECOVERY Collaborative Group, Horby P, Lim WS, et al. Dexamethasone in Hospitalized Patients with Covid-19 - Preliminary Report. N Engl J Med 2020;

4. Tomazini BM, Maia IS, Cavalcanti AB, et al. Effect of Dexamethasone on Days Alive and Ventilator-Free in Patients With Moderate or Severe Acute Respiratory Distress Syndrome and COVID-19: The CoDEX Randomized Clinical Trial. JAMA 2020;324(13):1307-16.

5. WHO Rapid Evidence Appraisal for COVID-19 Therapies (REACT) Working Group, Sterne JAC, Murthy S, et al. Association Between Administration of Systemic Corticosteroids and Mortality Among Critically III Patients With COVID-19: A Meta-analysis. JAMA 2020;324(13):1330-41.

6. Scientific and Standardization Committee communication: Clinical guidance on the diagnosis, prevention, and treatment of venous thromboembolism in hospitalized patients with COVID-19 Spyropoulos - 2020 - Journal of Thrombosis and Haemostasis - Wiley Online Library [Internet]. [cited 2020 Nov 27];Available from: https://onlinelibrary.wiley.com/doi/full/10.1111/jth.14929

7. Wichmann D, Sperhake J-P, Lütgehetmann M, et al. Autopsy Findings and Venous Thromboembolism in Patients With COVID-19: A Prospective Cohort Study. Ann Intern Med 2020;173(4):268-77.

8. Lodigiani C, lapichino G, Carenzo L, et al. Venous and arterial thromboembolic complications in COVID19 patients admitted to an academic hospital in Milan, Italy. Thromb Res 2020;191:9-14.

9. Miesbach W, Makris M. COVID-19: Coagulopathy, Risk of Thrombosis, and the Rationale for Anticoagulation. Clin Appl Thromb Off J Int Acad Clin Appl Thromb 2020;26:1076029620938149.

10. Menter T, Haslbauer JD, Nienhold R, et al. Postmortem examination of COVID-19 patients reveals diffuse alveolar damage with severe capillary congestion and variegated findings in lungs and other organs suggesting vascular dysfunction. Histopathology 2020;77(2):198-209.

11. Contou D, Fraissé M, Pajot O, Tirolien J-A, Mentec H, Plantefève G. Comparison between first and second wave among critically ill COVID-19 patients admitted to a French ICU: no prognostic improvement during the second wave? Crit Care Lond Engl 2021;25(1):3.

12. Le Gall JR, Lemeshow S, Saulnier F. A new Simplified Acute Physiology Score (SAPS II) based on a European/North American multicenter study. JAMA 1993;270(24):2957-63.

13. Vincent JL, Moreno R, Takala J, et al. The SOFA (Sepsis-related Organ Failure Assessment) score to describe organ dysfunction/failure. On behalf of the Working Group on Sepsis-Related Problems of the European Society of Intensive Care Medicine. Intensive Care Med 1996;22(7):707-10. 
14. Vm R, Gd R, Bt T, et al. Acute respiratory distress syndrome: the Berlin Definition [Internet]. JAMA. 2012 [cited 2021 Jan 26];307(23). Available from: https://pubmed.ncbi.nlm.nih.gov/22797452/

15. R Core Team (2018). R: A language and environment for statistical computing. R Foundation for Statistical Computing, Vienna, Austria. URL https://www.R-project.org/.

16. Bravata DM, Perkins AJ, Myers LJ, et al. Association of Intensive Care Unit Patient Load and Demand With Mortality Rates in US Department of Veterans Affairs Hospitals During the COVID-19 Pandemic. JAMA Netw Open 2021;4(1):e2034266.

17. Auld SC, Caridi-Scheible M, Blum JM, et al. ICU and Ventilator Mortality Among Critically III Adults With Coronavirus Disease 2019. Crit Care Med 2020;48(9):e799-804.

18. Rouzé A, Martin-Loeches I, Povoa P, et al. Relationship between SARS-CoV-2 infection and the incidence of ventilator-associated lower respiratory tract infections: a European multicenter cohort study. Intensive Care Med 2021;

19. Luyt C-E, Sahnoun T, Gautier M, et al. Ventilator-associated pneumonia in patients with SARS-CoV-2associated acute respiratory distress syndrome requiring ECMO: a retrospective cohort study. Ann Intensive Care 2020;10(1):158.

20. Brochard L, Lefebvre J-C, Cordioli RL, Akoumianaki E, Richard J-CM. Noninvasive ventilation for patients with hypoxemic acute respiratory failure. Semin Respir Crit Care Med 2014;35(4):492-500.

21. Brochard L, Slutsky A, Pesenti A. Mechanical Ventilation to Minimize Progression of Lung Injury in Acute Respiratory Failure. Am J Respir Crit Care Med 2017;195(4):438-42.

22. Marvisi M, Ferrozzi F, Balzarini L, Mancini C, Ramponi S, Uccelli M. First report on clinical and radiological features of COVID-19 pneumonitis in a Caucasian population: Factors predicting fibrotic evolution. Int J Infect Dis IJID Off Publ Int Soc Infect Dis 2020;99:485-8.

23. Huang W, Wu Q, Chen Z, et al. The potential indicators for pulmonary fibrosis in survivors of severe COVID-19. J Infect 2020;

24. Ferrando-Vivas P, Doidge J, Thomas K, et al. Prognostic Factors for 30-Day Mortality in Critically III Patients With Coronavirus Disease 2019: An Observational Cohort Study. Crit Care Med 2021;49(1):10211.

\section{Tables}


Table 1: Clinical, biological and radiological features of patients the day of ICU admission

\begin{tabular}{|c|c|c|c|c|}
\hline & $\begin{array}{l}\text { All } \\
N=187\end{array}$ & $\begin{array}{l}\text { First wave } \\
n=31\end{array}$ & $\begin{array}{l}\text { Second wave } \\
n=156\end{array}$ & $\mathrm{p}$-value \\
\hline Age (years) & $\begin{array}{l}64.0 \\
{[54.5 ; 71.0]}\end{array}$ & $\begin{array}{l}68.0 \\
{[59.5 ; 75.5]}\end{array}$ & $\begin{array}{l}64.0 \\
{[53.0 ; 71.0]}\end{array}$ & 0.06 \\
\hline Male & $129(69.0 \%)$ & $22(71.0 \%)$ & $107(68.6 \%)$ & 0.96 \\
\hline age_categories (years): & & & & 0.39 \\
\hline$[18,50[$ & $34(18.2 \%)$ & $3(9.68 \%)$ & $31(19.9 \%)$ & \\
\hline$[50,60[$ & $25(13.4 \%)$ & $5(16.1 \%)$ & $20(12.8 \%)$ & \\
\hline$[60,70[$ & $68(36.4 \%)$ & $10(32.3 \%)$ & $58(37.2 \%)$ & \\
\hline$[70$ & $60(32.1 \%)$ & $13(41.9 \%)$ & $47(30.1 \%)$ & 0.003 \\
\hline Body Mass Index $\left(\mathrm{kg} / \mathrm{m}^{2}\right)$ & $\begin{array}{l}29.4 \\
{[26.1 ; 34.2]}\end{array}$ & $\begin{array}{l}27.2 \\
{[24.7 ; 28.9]}\end{array}$ & $\begin{array}{l}30.9 \\
{[26.5 ; 34.6]}\end{array}$ & 0.01 \\
\hline $\begin{array}{l}\text { Time } 1^{\text {st }} \text { symptoms - ICU. admission } \\
\text { (days) }\end{array}$ & $\begin{array}{l}8.00 \\
{[5.50 ; 11.0]}\end{array}$ & $\begin{array}{l}8.00 \\
{[5.50 ; 12.0]}\end{array}$ & $\begin{array}{l}7.50 \\
{[5.75 ; 11.0]}\end{array}$ & 0.49 \\
\hline
\end{tabular}

\section{Comorbidity}

Hypertension $\mathrm{n}(\%)$

Diabetes $\mathrm{n}(\%)$

Other Cardiac disease $\mathrm{n}(\%)$

Chronic kidney disease $\mathrm{n}(\%)$

Malignancy

Number of comorbidities

\begin{tabular}{llll}
$118(63.1 \%)$ & $20(64.5 \%)$ & $98(62.8 \%)$ & 1.0 \\
\hline $98(52.4 \%)$ & $14(45.2 \%)$ & $84(53.8 \%)$ & 0.49 \\
\hline $20(10.7 \%)$ & $3(9.68 \%)$ & $17(10.9 \%)$ & 1.0 \\
\hline $25(13.4 \%)$ & $1(3.23 \%)$ & $24(15.4 \%)$ & 0.08 \\
$12(6.42 \%)$ & $1(3.23 \%)$ & $11(7.05 \%)$ & 0.69 \\
2.00 & 1.00 & 2.00 & 0.2 \\
{$[1.00 ; 2.00]$} & {$[1.00 ; 2.00]$} & {$[1.00 ; 3.00]$} &
\end{tabular}

\section{Previous treatment}

RAAS inhibitors $\mathrm{n}(\%)$

Metformin $\mathrm{n}(\%)$

$59(31.6 \%)$

$12(38.7 \%)$

$47(30.1 \%)$

0.47

$42(22.5 \%)$

$9(29.0 \%)$

$33(21.2 \%)$

0.47

\section{Clinical data at Day 1}

Temperature $\left({ }^{\circ} \mathrm{C}\right)$

38.0

[37.1;38.5]

38.3

Respiratory rate (/min.)

34.0

[28.0;40.0]

[37.8;39.2]

37.8

[37.0;38.3]

Diarrhea $\mathrm{n}(\%)$

$37(20.2 \%)$

31.0

[25.0;35.5]

34.0

[29.0;40.0]

0.04

$6(19.4 \%)$

31 (20.4\%)

1.0 


\begin{tabular}{|c|c|c|c|c|}
\hline Confusion n(\%) & $16(8.74 \%)$ & $2(6.45 \%)$ & 14 (9.21\%) & 1.0 \\
\hline $\mathrm{PaO} 2 / \mathrm{FiO} 2$ at D1 $(\mathrm{n}=68 / 72)$ & $\begin{array}{l}120 \\
{[90.0 ; 180]}\end{array}$ & $\begin{array}{l}168 \\
{[116 ; 215]}\end{array}$ & $\begin{array}{l}110 \\
{[88.5 ; 160]}\end{array}$ & 0.04 \\
\hline SAPS II & $\begin{array}{l}34.0 \\
{[24.0 ; 46.0]}\end{array}$ & $\begin{array}{l}32.0 \\
{[24.0 ; 47.0]}\end{array}$ & $\begin{array}{l}34.0 \\
{[24.0 ; 45.2]}\end{array}$ & 0.87 \\
\hline SOFA & $\begin{array}{l}4.00 \\
{[3.00 ; 8.00]}\end{array}$ & $\begin{array}{l}4.00 \\
{[3.00 ; 8.00]}\end{array}$ & $\begin{array}{l}4.50 \\
{[3.00 ; 8.00]}\end{array}$ & 0.89 \\
\hline \multicolumn{5}{|l|}{ Biological data at Day 1} \\
\hline Hemoglobin (g/L) & $\begin{array}{l}12.4 \\
{[11.0 ; 13.8]}\end{array}$ & $\begin{array}{l}12.8 \\
{[11.2 ; 14.4]}\end{array}$ & $\begin{array}{l}12.4 \\
{[10.9 ; 13.6]}\end{array}$ & 0.24 \\
\hline Platelets (G/L) & $\begin{array}{l}222 \\
{[168 ; 294]}\end{array}$ & $\begin{array}{l}186 \\
{[146 ; 238]}\end{array}$ & $\begin{array}{l}230 \\
{[177 ; 294]}\end{array}$ & 0.02 \\
\hline Leucocytes (G/L) & $\begin{array}{l}9.20 \\
{[6.60 ; 11.6]}\end{array}$ & $\begin{array}{l}6.90 \\
{[5.85 ; 8.85]}\end{array}$ & $\begin{array}{l}9.60 \\
{[7.00 ; 11.8]}\end{array}$ & $<0.001$ \\
\hline Lymphocytes (G/L) & $\begin{array}{l}0.95 \\
{[0.62 ; 1.27]}\end{array}$ & $\begin{array}{l}1.10 \\
{[0.59 ; 1.23]}\end{array}$ & $\begin{array}{l}0.91 \\
{[0.62 ; 1.27]}\end{array}$ & 0.63 \\
\hline DDimers $(\mu \mathrm{g} / \mathrm{mL}) \mathrm{n}=30$ & $\begin{array}{l}1.47 \\
{[0.96 ; 3.33]}\end{array}$ & $\begin{array}{l}1.88 \\
{[1.06 ; 3.86]}\end{array}$ & $\begin{array}{l}1.42 \\
{[0.92 ; 2.66]}\end{array}$ & 0.13 \\
\hline AST UI/L & $\begin{array}{l}57.0 \\
{[38.8 ; 86.5]}\end{array}$ & $\begin{array}{l}65.0 \\
{[52.0 ; 101]}\end{array}$ & $\begin{array}{l}56.0 \\
{[37.0 ; 86.0]}\end{array}$ & 0.15 \\
\hline ALT UI/L & $\begin{array}{l}40.0 \\
{[25.0 ; 63.0]}\end{array}$ & $\begin{array}{l}43.0 \\
{[34.0 ; 64.0]}\end{array}$ & $\begin{array}{l}39.0 \\
{[25.0 ; 62.5]}\end{array}$ & 0.39 \\
\hline $\mathrm{CRP}(\mathrm{mg} / \mathrm{L})$ & $\begin{array}{l}162 \\
{[84.8 ; 267]}\end{array}$ & $\begin{array}{l}165 \\
{[100 ; 261]}\end{array}$ & $\begin{array}{l}161 \\
{[84.0 ; 273]}\end{array}$ & 0.97 \\
\hline Creatinin $(\mu \mathrm{mol} / \mathrm{L})$ & $\begin{array}{l}95.0 \\
{[72.2 ; 151]}\end{array}$ & $\begin{array}{l}88.0 \\
{[70.0 ; 110]}\end{array}$ & $\begin{array}{l}100 \\
{[73.0 ; 158]}\end{array}$ & 0.13 \\
\hline CPK (UI/L) & $\begin{array}{l}332 \\
{[154 ; 960]}\end{array}$ & $\begin{array}{l}548 \\
{[168 ; 1368]}\end{array}$ & $\begin{array}{l}293 \\
{[152 ; 894]}\end{array}$ & 0.21 \\
\hline LDH (UI/L) & $\begin{array}{l}560 \\
{[465 ; 693]}\end{array}$ & $\begin{array}{l}591 \\
{[464 ; 682]}\end{array}$ & $\begin{array}{l}557 \\
{[468 ; 693]}\end{array}$ & 0.90 \\
\hline Troponin (ng/mL) & $\begin{array}{l}0.02 \\
{[0.01 ; 0.06]}\end{array}$ & $\begin{array}{l}0.02 \\
{[0.01 ; 0.06]}\end{array}$ & $\begin{array}{l}0.03 \\
{[0.01 ; 0.06]}\end{array}$ & 0.62 \\
\hline \multicolumn{4}{|c|}{$\%$ infiltrate on chest computed tomography } & 0.23 \\
\hline$\leq 25 \%$ & $14(8.14 \%)$ & $1(3.57 \%)$ & $13(9.03 \%)$ & \\
\hline $26-50 \%$ & $58(33.7 \%)$ & $6(21.4 \%)$ & $52(36.1 \%)$ & \\
\hline $51-75 \%$ & $55(32.0 \%)$ & $13(46.4 \%)$ & $42(29.2 \%)$ & \\
\hline$>75 \%$ & 45 (26.2\%) & $8(28.6 \%)$ & 37 (25.7\%) & \\
\hline
\end{tabular}


footnotes: Results are number $\mathrm{n}$ (percentage) of patients for categorical variables and median (q1-q3) for continuous variables. p-values were obtained using chi-square or Fisher's exact tests for categorical variables and using Student's t-test or Wilcoxon's rank-sum test for continuous variables

First wave: March-May 2020, second wave: August-October 2020, RAAS: Renin Angiotensin system BMI: Body mass index, SAPSII: simplified acute physiology score, SOFA: Sepsis-related Organ Failure Assessment, CRP: C-reactive-protein, AST: Aspartate aminotransferase, ALT: Alanine aminotransferase, LDH: lactate deshydrogenase CPK: Craatin PhosphoKinase. Day 1 is the first day of admission in Intensive care Unit 
Table 2. ICU management, complications and outcome between first and second wave $(\mathrm{N}=187)$

$\begin{array}{llll}\text { All } & \text { First wave } & \begin{array}{l}\text { Second } \\ \text { wave }\end{array} & \begin{array}{l}\mathrm{p} \text { - } \\ \text { value }\end{array} \\ \mathrm{N}=187 & \mathrm{n}=31 & \mathrm{n}=156 & \end{array}$

\section{Oxygen administration within 24 first hours}

\begin{tabular}{llll} 
Standard oxygen therapy & $\begin{array}{l}35 \\
(19.00 \%)\end{array}$ & $\begin{array}{l}17 \\
(54.8 \%)\end{array}$ & $\begin{array}{l}18 \\
(11.62 \%)\end{array}$ \\
Mechanical ventilation & $\begin{array}{l}72 \\
(40.90 \%)\end{array}$ & $\begin{array}{l}14 \\
(45.2 \%)\end{array}$ & $\begin{array}{l}58 \\
(38.90 \%)\end{array}$ \\
\hline High flow oxygen & $\begin{array}{l}65 \\
(34.90 \%)\end{array}$ & $0(0.00 \%)$ & 65 \\
& & $(41.90 \%)$ \\
\hline Non-invasive ventilation & $\begin{array}{l}14 \\
(7.95 \%)\end{array}$ & $0(0.00 \%)$ & $14(9.40 \%)$
\end{tabular}

\section{ARDS classification}

$$
\text { mild }
$$

moderate

severe

Pulmonary embolism

Mechanical ventilation required during ICU

\section{Complications \& management $(n=119)$}

Time between hospital admission \& mechanical ventilation (days)

Time between ICU admission \& mechanical ventilation (days)

Renal replacement therapy

Continuous neuromuscular blockers

Prone position

ECMO
14

$(17.3 \%)$

36

$(44.4 \%)$

31

$(38.3 \%)$

25

$(13.7 \%)$

119

$(64.0 \%)$
$6(33.3 \%) \quad 8(12.7 \%)$

$7(38.9 \%)$

$29(46.0 \%)$

$5(27.8 \%)$

$26(41.3 \%)$

$7(22.6 \%)$

$18(11.8 \%)$

0.14 
Norepinephrine

86

21

65

$(73.50 \%)$

$(95.50 \%)$

$(68.40 \%)$

0.02

\section{Infectious complications}

\begin{tabular}{lllll} 
Ventilator associated pneumonia & 56 & 14 & $42(47.2 \%)$ & 0.25 \\
& $(50.5 \%)$ & $(63.6 \%)$ & & \\
\hline Bacteriemia & 39 & 14 & $25(30.1 \%)$ & 0.008 \\
& $(37.1 \%)$ & $(63.6 \%)$ & &
\end{tabular}

\section{Outcome}

D60 Mortality

$83(44.6 \%)$

$13(41.9 \%)$

$70(45.2 \%)$

0.92

Length of stay in ICU (days)

7.00

14.0

$[4.00 ; 15.2]$

$[6.50 ; 28.0]$

6.00

0.002

Length of mechanical ventilation $(n=119)$

8.00

20.0

$[5.00 ; 17.0]$

[12.8;23.2]

$[4.00 ; 13.0]$

7.00

$<0.001$

Results are median and [IQR 25-75] for continuous variables and number $\mathrm{n}(\%)$ for categorical variables; $\mathrm{p}$ values were obtained using chi-square or Fisher's exact tests for categorical variables and using Student's t-test or Wilcoxon's rank-sum test for continuous variables First wave: March-May 2020, Second wave: August-October 2020, ARDS: Acute respiratory distress syndrome, ICU: Intensive care unit, ECMO: extracorporeal membrane oxygenation

Table 3. Multivariable logistic regression analyses of factors associated with 60 days mortality for patients who required Mechanical ventilation during ICU $(\mathrm{N}=109)$

\begin{tabular}{|lll|}
\hline & OR $(95 \% \mathrm{Cl})$ & p-value \\
\hline Age & $1.03(1.0 . ; 1.1]$ & 0.1 \\
\hline SOFA score & $1.34[1.15 ; 1.61]$ & $<0.001$ \\
\hline Number of comorbidities & $1.63[1.1 ; 2.6]$ & 0.04 \\
\hline Time to mechanical ventilation (days) after ICU admission & $1.64[1.2 ; 2.4]$ & 0.005 \\
\hline $\begin{array}{l}\text { Results from univariable analyses are presented in the appendix. OR and 95\%Cl: odds ratios and 95\% } \\
\begin{array}{l}\text { Confidence interval were calculated from the multivariable model after deletion of patients with } \\
\text { missing data (N=9); } 76 \text { (64\%) patients died within 2 months, SOFA: Sequential Organ Failure }\end{array}\end{array}$ \\
\hline \begin{tabular}{l} 
Assessment, VAP: Ventilator acquired pneumonia, ICU: Intensive Care Unit \\
\hline
\end{tabular}
\end{tabular}


Table 4: Clinical features of patients the day of ICU admission who needed more than 4 days of non invasive ventilation who recovered vs those who failed and finally required mechanical ventilation

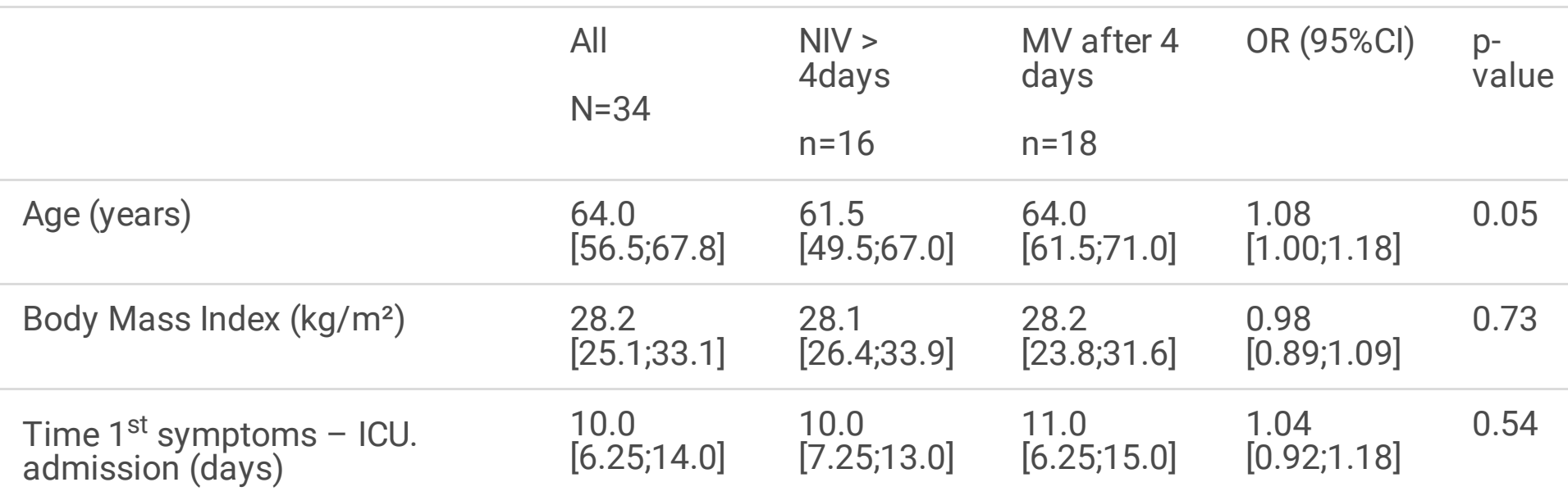

\section{Comorbidity}

Hypertension $n(\%)$

$21(61.8 \%) \quad 8(50.0 \%)$

$13(72.2 \%)$

2.50

$[0.60 ; 11.4]$

0.21

Diabetes n (\%)

$17(50.0 \%) \quad 6(37.5 \%)$

$11(61.1 \%)$

2.52

$[0.63 ; 11.0]$

Number of comorbidities

3.00[

$1.25 ; 4.00]$

2.00

[1.00;3.00]

3.50

$[2.25 ; 5.00]$

1.91

$[1.12 ; 3.27]$

0.19

0.01

\section{Clinical data at Day 1}

Fever $\left({ }^{\circ} \mathrm{C}\right)$

37.6

37.6

37.2

[37.0;38.0]

[37.0;38.0]

[37.0;38.1]

0.74

0.48

Respiratory rate (/min.) $n=36$

$34.0(5.93)$

34.6

(6.23)

$33.4(5.78)$

[0.32;1.73]

SAPS II

30.0

25.0

37.0

0.97

0.57

[0.86;1.09]

$[24.0 ; 37.0] \quad[22.0 ; 30.2] \quad[26.0 ; 46.0] \quad[1.03 ; 1.29]$

SOFA

$$
3.00
$$

$[2.00 ; 5.00]$

3.00

$[2.00 ; 4.00]$

5.00

$[3.00 ; 8.00]$

1.51

$[1.03 ; 2.22]$

1.15

0.01

footnotes: Results are number $n$ (percentage) of patients for categorical variables and median (q1-q3) for continuous variables.

OR odds ratio and $95 \% \mathrm{Cl}$ : $95 \%$ confidence intervals were obtained using univariate logistic regression.

Day 1 is the first day of admission in Intensive care Unit

NIV: Non invasive ventilation, MV: Mechanical ventilation, SAPSII: simplified acute physiology score, SOFA: Sepsis-related Organ Failure Assessment,

\section{Figures}



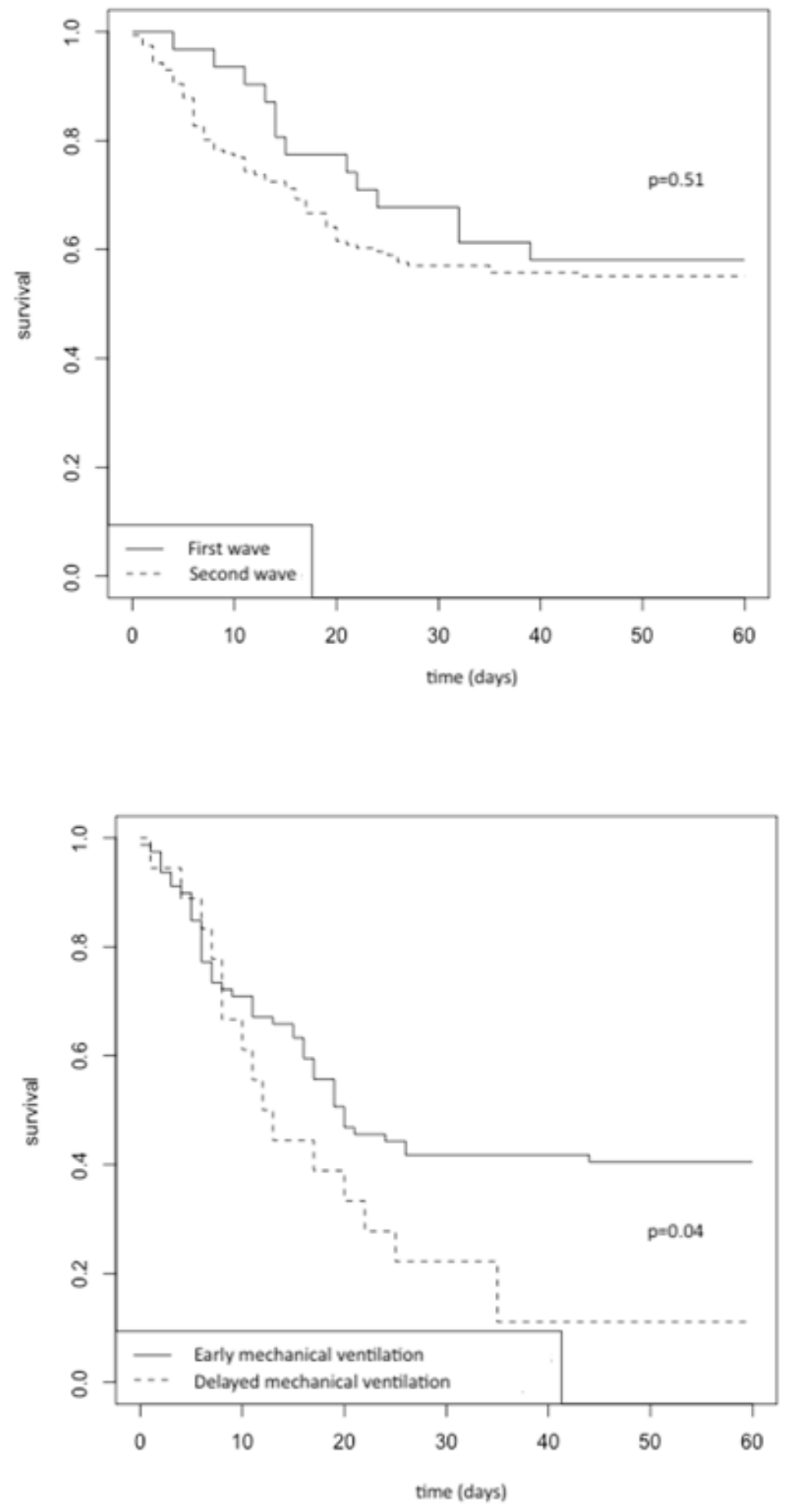

\section{Figure 1}

A: Kaplan Meier curve of COVID-1S patients: first $(n=31)$ versus second wave $(n=156)$ B: Kaplan Meier curve of COVID-19 ICU patients requiring mechanical ventilation: delayed (>4days after Dexarmethason administration, $n=18$ ) versus early ( $<4$ days after dexamethason administration, $n=79$ )

\section{Supplementary Files}


This is a list of supplementary files associated with this preprint. Click to download.

- TableS1.docx

- Tables2FM.docx 